\title{
FROM SELENIUM TO SELENOPROTEINS AND THEIR ROLE - MINIREVIEW
}

\author{
ALEXANDRA GABRIELA CAȚIANIS ${ }^{1}$, BOGDANA VIRGOLICI ${ }^{2}$, \\ BEATRICE CARMEN DOGARU ${ }^{3}$, HORIA VIRGOLICI ${ }^{4}$, MARIA MOHORA ${ }^{5}$ \\ 1,2,3,4,5 “Carol Davila” University of Medicine and Pharmacy Bucharest
}

\begin{abstract}
Keywords: $\quad$ selenium, Abstract: Selenium (SE) is an essential micronutrient fulfilling a number of biological roles, being selenoprotein, oxidative integrated as selenocysteine in the primary structure of certain selenoproteins. The Selenocysteine is stress synthesized and inserted into proteins during the translational process of the RNAm by a mechanism which involves converting a stop codon for certain proteins into a meaningful codon. Only 25 genes encoding selenocysteine-incorporating proteins have been identified in the human genome. The selenoprotein families including glutathione peroxidase, iodothyronine deiodinase and thioredoxin reductases are known as enzymes engaged in redox processes. The selenoprotein P (SEPPI) is a hepatokine produced by the liver, an extracellular glycoprotein, which is not part of these families. The purpose of this Article is to present the form of distribution of selenium and its physiological role in the body.
\end{abstract}

\section{INTRODUCTION}

Selenium (Se) was identified as a chemical element in 1817 by the Swedish chemist Berzelius and further studied by other researchers who found that Se is an essential element for many life forms, including humans.(1) The name of selenium was given by Berzelius from the word "selene" which means "goddess of the Moon" in Greek mythology.

Selenium was initially known as a toxic element, its toxicity varying from species to species and is dependent on the $\mathrm{pH}$ of the medium, its concentration and the chemical structure of the compounds containing Se. Integrated in the structure of certain selenoproteins, the selenium can act as antioxidant (in nano-micromolar concentrations), helping to regulate the various biological processes in the organism, or it can be a potential pro-oxidant when its concentration exceeds the maximum requirement for the synthesis of selenoproteins.(2) Although Se toxicity is possible, the deficiency has been associated with a number of conditions: increased risk of cancer and infections, cardiovascular disease, male infertility, low immunity, neurological and thyroid disorders.(3)

Selenium is transferred from the soil to the body of animals through plants that capture this element in its inorganic form and turn it into organic compounds. The amount of selenium in food varies widely depending on the amount of selenium in the soil of that region.

In higher organisms, selenium is integrated as selenocysteine into the primary structure of some selenoproteins. Selenocysteine is synthesized and inserted into proteins during the ${ }_{\mathrm{m}} \mathrm{RNA}$ translation process, through a mechanism that involves the transformation of a stop codon for certain proteins into a sense codon. Only 25 genes encoding selenocysteine-incorporating proteins have been identified in the human genome.(4)

Selenoprotein P (SEPP1) is a hepatokine produced by the liver, with both an antioxidant and a selenium transporter role from the liver to peripheral tissues.(5) Regarding the status of selenium plasma levels, selenoprotein $\mathrm{P}$ was found to be a more accurate marker than the previously used enzyme, GPx3.

2. The chemical forms of selenium

Selenium is found in the structure of inorganic and organic compounds. Selenium is in the same group as oxygen, sulfur and tellurium with which it is related as properties. Like sulfur it can form Se-Se bridges. Of the various oxidation states $(-2,+2,+4$ and +6$)$ selenium is found most commonly in states +4 and +6 in the salts of selenous acids $\left(\mathrm{H}_{2} \mathrm{SeO}_{3}\right)$ and selenic $\left(\mathrm{H}_{2} \mathrm{SeO}_{4}\right)$ and -2 in selenite $\left(\mathrm{H}_{2} \mathrm{Se}\right)$. Selenious and selenic acids are hydrated forms of selenium oxides: selenium dioxide $\left(\mathrm{SeO}_{2}\right)$ and selenium trioxide $\left(\mathrm{SeO}_{3}\right)$. The latter can be converted to selenium dioxide by heating.

Plants capture selenium from the soil in its inorganic form (selenite and selenate) and turn it into organic compounds: (amino acids) selenomethionine (SeMet) and selenocysteine (Sec) [6] and methyselenol $\left(\mathrm{CH}_{3} \mathrm{SeH}\right)$.

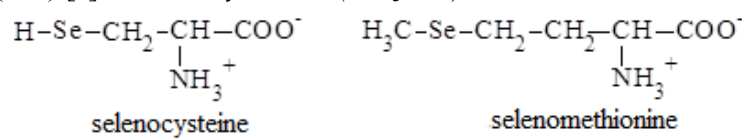

\section{Selenium in biological systems}

In the human body, selenium is found as a substitute for sulfur in cysteine and methionine, the two amino acids being called selenocysteine and selenomethionine. In inorganic form selenium is present in the body in the form of selenite and selenate.

Selenium can enter the human body by skin, respiratory and intestinal levels. Selenate and selenomethionine are absorbed without changes in the intestine, while selenite and selenocysteine are metabolized.

Among the organic forms, selenomethionine, which cannot be synthesized by the human body, predominates in the diet. Selenomethionine, which cannot be metabolized during

${ }^{1}$ Corresponding author: Carmen Beatrice Dogaru, B-dul. Eroii Sanitari, Nr .8, Bucureşti, România, E-mail: carmenbeatriced@gmail.com, Phone: $+40748677802$

Article received on 13.07.2020 and accepted for publication on 24.08.2020 


\section{CLINICAL ASPECTS}

digestion, is absorbed in the intestine by a mechanism similar to the absorption of amino acids with a neutral radical.(7) After intestinal absorption, selenomethionine can be incorporated into selenoproteins, nonspecifically, instead of methionine, at a high $\mathrm{SeMet} / \mathrm{Met}$ ratio.(8,9) Selenomethionine incorporated into muscle proteins, erythrocytes especially in hemoglobin, pancreas, liver, kidneys, stomach and gastrointestinal mucosa $(7,8,9,10,11)$ may be a form of selenium storage in the body, with a slower turnover than selenite and selenate. Se-met is also significantly retained by the brain.(9) Se-met supplements compared to selenite or selenate have effects on lymphocyte proliferation.(12)

Once in the blood, selenium is incorporated as a selenocysteine, known as the 21 st natural amino acid, into approximately 25 selenoproteins encoded by 25 genes (4), and selenite is concentrated at the erythrocyte level by an active transport mechanism.

\section{Selenoprotein biosynthesis}

Selenoprotein synthesis is a complex process that has several stages, involves a set of specialized cofactors for their synthesis and depends on the intake of selenium in the diet.(13)

Energy consumption for the synthesis of cofactors required for selenoprotein synthesis suggests the importance of this family of proteins for cellular activity and is the raison d'être of selenoproteins despite their costly synthesis.(14)

The selenium is incorporated into proteins covalently in the form of selenocysteine, not by ionic association as in most metals. The selenocysteine insertion process uses a unique mechanism that requires decoding the UGA codon from the ${ }_{\mathrm{m}} \mathrm{RNA}$, normally involved in translational completion.(15)

The transformation of the UGA codon from a stop codon to a signal for selenocysteine incorporation is mediated, in eukaryotes, by several essential elements: specific $\mathrm{RNA}_{t}$ molecules, the nucleotide sequence for selenocysteine insertion (SECIS) in the non-translating region (3' UTR) of ${ }_{m}$ RNA, UGA codon, a selenocysteine-specific elongation factor (eEFSec), a SECIS sequence binding protein for selenocysteine insertion (SBP2).(16)

The $\mathrm{RNA}_{t}$ for selenocysteine is initially loaded with serine by seril-RNA $\mathrm{A}_{t}$ synthetase. Serine is phosphorylated by a kinase and phosphoseryl-RNA $\mathrm{A}_{t}^{\text {(ser) }}$ sec is converted to selenocysteinyl- $\mathrm{ARN}_{\mathrm{t}}^{(\mathrm{ser})}$ by Sec-synthase in the presence of monoselenophosphate. Monoselenophosphate is formed in the presence of selenophosphate synthetase 2 (SPS 2) from selenide from inorganic $\mathrm{Se}$ or from tissue and dietary forms of selenium.(17) Selenocysteine is broken down by selenocysteine into L-alanine and selenide.(18)

An important aspect of selenocysteine synthesis is represented by the presence of the enzyme SPS 2, which itself is a selenoprotein. The enzyme SPS 2 is directly involved in the synthesis of monoselenophosphate which is the active selenium donor, necessary for the synthesis of selenocysteine.(17) (figure no. 1).

Tissue and dietary forms of selenium are converted to selenide $\left(\mathrm{H}_{2} \mathrm{Se}\right)$. It is converted to monoselenophosphate in the presence of selenophosphate synthetase 2. Monoselenophosphate converts serine bound to $\mathrm{RNA}_{\mathrm{t}}^{(\mathrm{ser}) \mathrm{sec}}$, after its phosphorylation by a kinase, to selenocysteinyl$\mathrm{RNA}_{\mathrm{t}}^{(\mathrm{ser})}$ sec which inserts selenocysteine into the growing peptide chain.(adapted after).(17)

Selenocysteine is incorporated into selenoproteins only if the UGA codon is in a selenocysteine insertion sequence (SECIS), defined stem-loop in the non-translating region $\left(3^{\prime}\right.$ UTR) of ${ }_{m}$ RNA.(19) The specificity of selenocysteine incorporation is assured by a specific elongation factor for selenocysteine (eEFSec) and a binding protein for selenocysteine insertion(SBP2).(20)
Figure no. 1. The pathway of selenocysteine biosynthesis in mammals

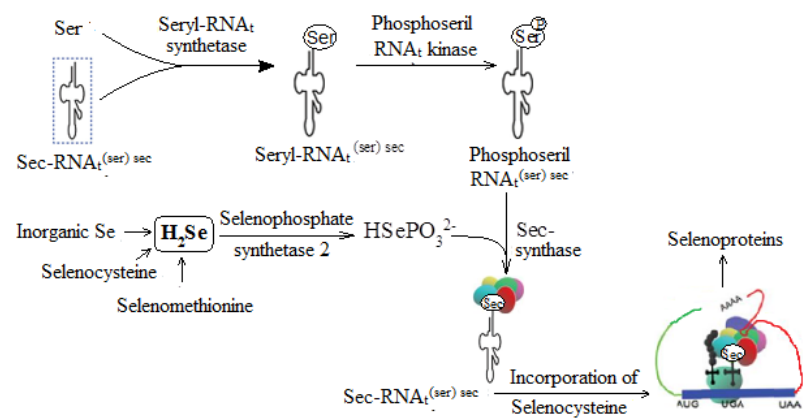

Selenocysteine is incorporated into selenoproteins only if the UGA codon is in a selenocysteine insertion sequence (SECIS), defined stem-loop in the non-translating region (3' UTR) of ${ }_{m}$ RNA.(19) The specificity of selenocysteine incorporation is assured by a specific elongation factor for selenocysteine (eEFSec) and a binding protein for selenocysteine insertion(SBP2).(20)

The encoding gene of the glutathione peroxidase 1 was the first gene discovered to have the UGA codon, which corresponds to the position of selenocysteine in the protein sequence. Shortly after this discovery, it was identified that selenocysteine is inserted into the final protein through its own t-RNA molecule complementary to the UGA codon. Selenocysteine transport RNA is unique because it controls the expression of all selenoproteins, a process that is not identified for other t-RNAs belonging to other amino acids.(17)

Tissue disorders caused by statins could be caused by inhibition of selenoprotein synthesis because selenocysteine$\mathrm{RNA}_{t}{ }^{\text {(Ser)Sec }}$ requires for its activity isopentenylation with an intermediate of the cholesterol synthesis pathway.(21) Statins used therapeutically in hypercholesterolemia inhibit the synthesis of cholesterol, and thus reduce the synthesis of isopentenyl groups.(22) Myopathy and other side effects caused by statins are similar to the symptoms of selenium deficiency. This suggests that one of the mechanisms of tissue disorders caused by statins may be the inhibition of selenoprotein synthesis because selenocysteine- $\mathrm{RNA}_{t}{ }^{(\mathrm{Ser}) \mathrm{Sec}}$ requires isopentenylation for activity (figure no. 2) After the treatment of liver and muscle cells with various statins (atorvastatin, cerivastatin, and lovastatin) the amount of $\mathrm{RNA}_{\mathrm{m}}$ remained unchanged, suggesting that the posttranscriptional mechanism was influenced that led to the suppression of $\mathrm{GP}_{\mathrm{x}}$ and $\mathrm{N}$ selenoprotein biosynthesis was influenced.(23)

Figure no. 2. Isopentenylation of selenocysteinyl-RNA $A_{t}^{(\mathrm{Ser}) \mathrm{Sec}}$ with an intermediate in the cholesterol synthesis pathway

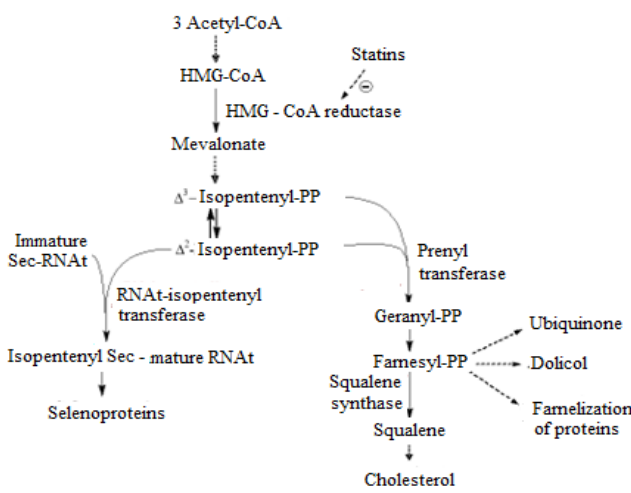

\section{Selenoprotein role}

Many proteins that include selenocysteine have an antioxidant role, helping to eliminate reactive oxygen species. 


\section{CLINICAL ASPECTS}

The higher acidity $\left(\mathrm{pK}_{\mathrm{a}}=5.47\right)$ and the lower reducing potential of cysteine make selenocysteine suitable for antioxidant proteins.(24)

Table no. 1. Selenoproteins in the human body

\begin{tabular}{|c|c|c|c|c|c|c|}
\hline Table no. 1. Selenoproteins in the human body & & \\
\hline & & & & & \\
\hline & & & & & & \\
\hline $\mathrm{GP}_{\mathrm{x}} 1 ; \mathrm{GP}_{\mathrm{x}} 2$ & $\mathrm{Tr}_{\mathrm{x}} \mathrm{R}_{1}$ & $\mathrm{DIO} 1$ & $\mathrm{SPS} 2$ & Sel P & Sep 15 & SelH \\
\hline $\mathrm{GP}_{\mathrm{x}} 3 ; \mathrm{GP}_{\mathrm{x}} 4$ & $\mathrm{Tr}_{\mathrm{x}} \mathrm{R}_{2}$ & $\mathrm{DIO} 2$ & & & SelN & Sell \\
\hline $\mathrm{GP}_{\mathrm{x} 6}$ & $\mathrm{Tr}_{\mathrm{x}} \mathrm{R}_{3}$ & $\mathrm{DIO}$ & & & SelM & SelO \\
\hline $\mathrm{SelK}$ & & & & & SelS & SelT \\
\hline $\mathrm{SelR}$ & & & & & & SelV \\
\hline $\mathrm{SelW}$ & & & & & & \\
\hline
\end{tabular}

The first enzyme identified in mammals containing Selenocysteine in the active center was glutathione peroxidase (GPx). The selenoprotein families, which include glutathione peroxidases, iodothyronine deiodinases and thioredoxin reductases, contain, in the active center, a single selenocysteine residue per protein molecule and are known as enzymes involved in redox processes.

Glutathione peroxidase is a family of selenoproteins that have 4 isoenzymes (GPx1-cytosolic, GPx2-gastrointestinal, GPx3-plasma, GPx4-phospholipid hydroperoxide glutathione peroxidase). Intracellular glutathione peroxidase (GSHPx-1) was the first selenoprotein discovered in mammals.(25)

Glutathione peroxidases are tetrameric enzymes, each monomer containing a selenium atom in the form of a selenocysteine at position 35 of the polypeptide chain. All isoenzymes are antioxidant, reduce $\mathrm{H}_{2} \mathrm{O}_{2}$ and convert lipid and phospholipid hydroperoxides into harmless products (water and alcohols), using glutathione (GSH) as a substrate, but differ in distribution and substrate specificity.(26)

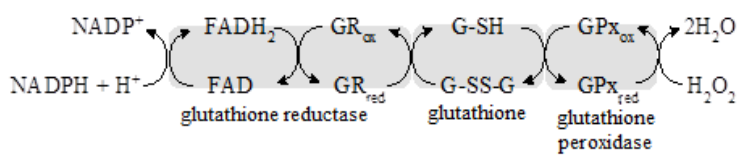

The reducing equivalents on NADPH (nicotinamide adenine dinucleotide phosphate) pass through the glutathione reductase system on glutathione and then into the glutathione peroxidase system which reduces hydrogen peroxide.

The iodothyronine family of deiodinases comprises 3 isoenzymes, two of them being activators: $\mathrm{DIO}_{1}$ and $\mathrm{DIO}_{2}$ (converts $\mathrm{T}_{4}$ to $\mathrm{T}_{3}$ ) and one inactivator: $\mathrm{DIO}_{3}$ which inactivates $\mathrm{T}_{3 .} .(27)$

Thioredoxin reductase (TR) $(28,29)$, (TR) is an enzyme that contains a selenocysteine residue in the terminal sequence and has three isoforms (TR 1, TR 2, TR 3). This catalyzes the reduction of NADPH-dependent thioredoxin as well as other oxidized cell constituents. Being a reducing enzyme with low substrate specificity, thioredoxin reductase contributes to redox homeostasis and is involved in the prevention and repair of disorders caused by oxidative stress generated by hydrogen peroxide. The activity of thioredoxin reductase in humans is influenced both by the selenium deficiency in the diet and by its excessive supplementation.

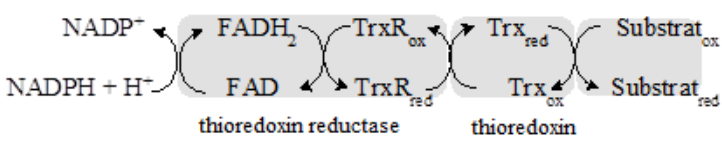

Selenoprotein $\mathbf{P}$ is the second most important plasma selenoprotein after GPx3 and is estimated to contain up to $50 \%$ of total plasma selenium. Of the total amount of approximately 8 $\mathrm{mg} \mathrm{Se} / \mathrm{dl}$ plasma contained in selenoproteins, 6-7 $\mathrm{mg} \mathrm{Se} / \mathrm{dl}$ plasma is contained in selenoprotein $\mathrm{P}$ and $1-2 \mathrm{mg} \mathrm{Se} / \mathrm{dl}$ plasma in GSHPx-3.(30,31). Nutritional deficiency of selenium causes a decrease in the concentration of Se in plasma below 8 $\mathrm{mg} / \mathrm{dl}$ (32) but also a decrease in the concentration of selenoprotein $\mathrm{P}$, which can be considered a biomarker of plasma selenium levels (31) more accurate than the previously used enzyme, GPx3.

SelP is different from other selenoproteins because incorporates many selenocysteine residues in the primary structure, with 10 selenocysteine residues being identified for the human protein. 4 isoenzymes that have the same amino acid sequence have been identified and characterized.(33)

Being synthesized by the liver and then secreted into plasma, selenoprotein $\mathrm{P}$ was initially considered a selenium transporter protein. Subsequent studies have shown that selenoprotein $\mathrm{P}$ does not bind and release Se in the way that transferrin binds and releases iron. In selenoproteins, selenium is covalently bound, and its release in order to be used by cells would require protein degradation.(33)

An important aspect in the performance of the selenium transporter protein function of selenoprotein $\mathrm{P}$ is the affinity of the protein for cell membranes.(35) Recent studies have shown that some tissues can pick up small molecules that contain selenium and others can pick up selenoprotein P. The absorption of selenium in the brain by selenoprotein $\mathrm{P}$ could explain why the brain is so resistant to selenium depletion. It can always extract the selenium it needs from the circulating selenoprotein P.(36)

Selenium plays an important role in the functioning of the brain. Selenium has been shown to influence cognitive function and emotional state. Removal of the selenoprotein $\mathrm{P}$ gene has led to decreased selenium levels in the brain and neuronal dysfunctions. $(37,38)$ Selenoprotein $\mathrm{P}$ can also promote neuronal cell survival. Changes in selenium status may have implications for Alzheimer's disease or Parkinson's disease.(39)

Originally identified as a plasma protein, SelP plays an important role in protecting the brain from oxidative stress. Local expression of SelP in the brain increases with age, suggesting its role in relieving oxidative stress in neurons and ependymal cells in the human brain.(40)

In addition to its role in the transport and distribution of selenium, SelP is a heavy metal chelator, forming complex non-toxic Se-Metal combinations, thus preventing neurotoxicity and increasing protection against oxidation reactions mediated by the peroxynitrite anion. Because it can directly reduce phospholipid hydroperoxides, as demonstrated in vitro, SelP could play an important antioxidant role. SelP has also been shown to protect endothelial cells and astrocytes against oxidative stress and to inhibit LDL oxidation.(41)

\section{CONCLUSIONS}

Selenium plays a number of essential roles in the human body. As part of a number of physiologically active selenoproteins, selenium has the role of protecting cells against the action of reactive forms of oxygen. Selenoprotein synthesis requires a set of cofactors and is dependent on selenium in the diet. The body's energy needs for the synthesis of cofactors and selenoproteins suggest the importance of these proteins for cell function. Knowing the role of selenoproteins in different pathologies (table no. 1): neuromuscular, cardiovascular, neurodegenerative, inflammatory, endocrine, can provide the strategy for their use in treating or preventing various diseases.

\section{REFERENCES}

1. Schwarz K, Foltz CM. Selenium as an integral part of factor 3 against dietary necrotic liver degeneration, J Am Chem Soc. 1957;79:3292-3293.

2. Vinceti M, Wei ET, Malagoli C, Bergomi M, Vivoli G. 


\section{CLINICAL ASPECTS}

Adverse health effects of selenium in humans, Rev Environ Health. 2001;16(4):233-51

3. Davis CD, Petra A, Tsuji PT, Milner JA. Selenoproteins and Cancer Prevention, Annu. Rev. Nutr. 2012;32:73-95.

4. Kryukov GV, Castellano S, Novoselov SV, Lobanov AV, Zehtab O. Characterization of mammalian selenoproteomes, Science. 2003;300:1439-43.

5. Burk RF, Hill KE, Motley AK. Selenoprotein Metabolism and Function: Evidence for More than One Function for Selenoprotein P. The Journal of Nutrition. 2003;133:1517S-1520S.

6. Sors TG, Ellis DR, Salt DE. Selenium uptake, translocation, assimilation and metabolic fate in plants, Photosynth Res. 2005;86:373-89.

7. Bakke AM, Tashjian DH, Wang CF, Lee SH, Bai SC, Hung SS. Competition between selenomethionine and methionine absorption in the intestinal tract of green sturgeon (Acipenser medirostris), AquatToxicol,https://www.ncbi.nlm.nih.gov/pubmed/

8. Hansson E, Jacobsson SO. Uptake of $(75 \mathrm{Se})$ slenomethionine in the tissues of the mouse studied by whole-body autoradiography. Biochim. Biophys. Acta, 1966; 115: 285-293.

9. Schrauzer NG. Selenomethionine: A Review of Its Nutritional Significance, Metabolism and Toxicity, The Journal of Nutrition. 2000;130:1653-1656.

10. Waschulewski IH, Sunde RA. Effect of dietary methionine on utilization of tissue selenium from dietary selenomethionine for glutathione peroxidase in the rat. Journal of Nutrition. 1988;118:367-374.

11. Oster O, Schmiedel G, Prellwitz W. Organ distribution of selenium in German adults, Biological Trace Element Research. 1988;15:23-45.

12. Reis JH, Gebert RR, Fortuoso BF, Santos DS, Souza CF, Baldissera MD, Tavernari FC, Paiano D, Da Silva AS. Selenomethionine as a dietary supplement for laying hens: Impacts on lipid peroxidation and antioxidant capacity in fresh and stored eggs. 2019;43:12957.

13. Ha HY, Alfulaij N, Berry MJ, Seale LS. From Selenium AbsorptiontoSelenoproteinDegradation, Biological Trace Element Research. 2019;192:26-37.

14. Böck A, Forchhammer K, Heider J, Leinfelder W, Sawers G, Veprek B, Zinoni F. Selenocysteine: the 21st amino acid. - NCBI, Microbiol. 1991;5:515-20.

15. Hatfield DL, Gladyshev VN. How selenium has altered our understanding of the genetic code, Mol Cell Biol. 2002;22:3565-76.

16. .Donovan J, Copeland PR. Selenocysteine Insertion Sequence Binding Protein 2L Is Implicated as a Novel Post-Transcriptional Regulator of Selenoprotein Expression. PLoS ONE, 2012; 7:e 35581.

17. Xu XM, Carlson BA, Irons R, Mix H, Zhong N, Gladyshev VN, Hatfield DL. Selenophosphate synthetase 2 is essential for selenoprotein biosynthesis, Biochem J. 2007;15:115-20.

18. Labunskyy VM, Hatfield DL, Gladyshev VN Selenoproteins: molecular pathways and physiological roles. Physiological Reviews. 2014;94:739-7.

19. Berry MJ, Banu L, Harney JW, Larsen PR. nctional characterization of the eukaryotic SECIS elements which direct selenocysteine insertion at UGA codons. The EMBO Journal. 1993;12:3315-22.

20. Donovan J, Copeland PR. The efficiency of selenocysteine incorporation is regulated by translation initiation factors. $J$ Mol Biol. 2010;400:659-664.

21. Moosmann B, Behl C. Selenoprotein synthesis and sideeffects of statins. - NCBI, Lancet. 2004;13;363(9412):892-
22. Patil D, Patwardhan B, Kumbhare K. Why and How Drugs Fail, Chap 2. Inovative Approaches in Drug Discovery, Ethnopharmacology, Systems Biology and Holistic Targeting, Book; 2017. p. 23-64.

23. Kromer A, Moosmann B. Statin-induced liver injury involves cross-talk between cholesterol and selenoprotein biosynthetic pathways. Mol Pharmacol. 2009;75(6):1421-9.

24. Bellinger FP, Raman AV, Reeves MA, Berry MJ. Regulation and function of selenoproteins in human disease, Biochem J. 2010;422(1):11-22.

25. Rotruck JT, Pope AL, Ganther HE, Swanson AB, Hafeman D, Hoekstra WG. Selenium: biochemical role as a component of glutathione peroxidase, Science. 1973;179:588-590.

26. Arthur JR. The glutathioneperoxidases. Cell Mol Life Sci. 2000;57:1825-1835.

27. Bianco AC, Salvatore D, Gereben B, Berry MJ, Larsen PR. Biochemistry, cellularand molecular biology, andphysiologicalroles theiodothyronineselenodeiodinases. Endocr. Rev. 2002;23:38-89.

28. Marshall AC, Kidd SE, Lamont-Friedrich SJ, Arentz G, Hoffmann P, Coad BR, Bruning JB. Structure, Mechanism, and Inhibition of Thioredoxin Reductase, Antimicrobial Agents and Chemotherapy. 2019;63(3).

29. Holmgren A. Antioxidant function of thioredoxinandglutaredoxinsystems. Antioxid. Redox Signal. 2000;2:811-20.

30. Burk RF, Hill KE.Selenoprotein P-expression, functions, and roles in mammals. Biochim Biophys Acta, 2009;1790:1441-447.

31. Hill KE, Xia Y, Akesson B, Boeglin ME, Bur RF.Selenoprotein $\mathrm{P}$ concentration in plasma is an index of selenium status in selenium-deficient and seleniumsupplemented Chinese subjects. J Nutr, 1996;126:138-145.

32. Xia Y, Hill KE, Burk RF. Biochemical studies of a selenium-deficient population in China: measurement of selenium, glutathione peroxidase and oxidant defenses in blood. J Nutr. 1989;119:1318-1326.

33. Burk RF, Hill KE. Selenoprotein P: an extracellular protein with unique physical characteristics and a role in selenium homeostasis. Annu. Rev. Nutr . 2005;25:215-235.

34. Motsenbocker MA, Tappel AL. A selenocysteinecontaining selenium-transport protein in rat plasma. Biochim Biophys Acta, 1982;719:147-153.

35. Wilson DS, Tappel AL. Binding of plasma selenoprotein $P$ to cell membranes. J. Inorg. Biochem. 1993;51:707-714.

36. Burk RF, Hill KE, Read R, Bellew T. Response of rat selenoprotein $\mathrm{P}$ to selenium administration and fate of its selenium. Am J Physiol, 1991;261:E26-E30.

37. Schweizer U, Bräuer AU, Köhrle J, Nitsch R, Savaskan NE. Selenium and brain function: a poorly recognized liaison., Brain Res Brain Res Rev. 2004;45(3):164-78.

38. Richardson DR. More roles for selenoprotein P: local selenium storage and recycling protein in the brain, Biochem J. 2005;386:E5

39. Chen J, Berry MJ. Selenium and selenoproteins in the brain and brain diseases. J. Neurochem, 2003;86:1-12.

40. Scharpf M, Schweizer U, Arzberger T, Roggendorf W, Schomburg L, Köhrle J. Neuronal and ependymal expression of selenoprotein $\mathrm{P}$ in the human brain. J Neural Transm. 2007;114:877-884.

41. Saito Y. Selenoprotein $P$ as an in vivo redox regulator: disorders related to its deficiency and excess, J. Clin. Biochem Nutr. 2020;66(1):1-7. 